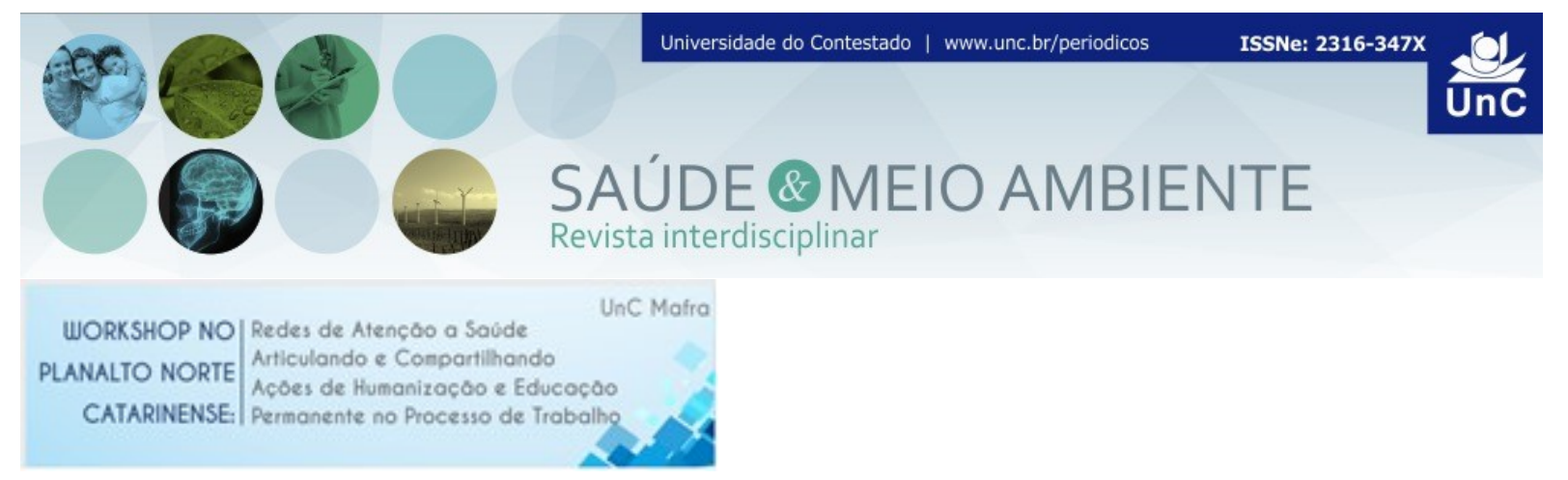

\title{
AGENDAMENTO COM ACOLHIMENTO E CLASSIFICAÇÃO DE RISCO NAS UNIDADES DE ESTRATÉGIA DE SAÚDE DA FAMÍLIA NO MUNÍCIPIO DE CANOINHAS-SC
}

\author{
Grasielly Cristina Alves ${ }^{1}$ \\ Rafaela Ciupka Valim²
}

\section{RESUMO}

INTRODUÇÃO: O atendimento aos portadores de quadros agudos, de natureza clínica, traumática ou psiquiátrica, deve ser prestado por todas as portas de entradas do SUS, ou seja, pelo conjunto das unidades básicas de saúde e suas equipes de Estratégia de Saúde da Família, pelas unidades hospitalares e móveis, possibilitando a resolução dos problemas de saúde dos pacientes ou transportando-os responsavelmente a um serviço de saúde hierarquizado e regulado. $O$ acolhimento propõe reorganizar o serviço no sentido de oferecer sempre uma resposta positiva ao problema de saúde apresentado pelo usuário. A classificação de risco é entendida como um processo dinâmico que consiste em identificar o risco/vulnerabilidade do usuário. Visto a necessidade da implantação do agendamento com classificação de risco nas unidades, os profissionais passaram por capacitações em educação permanente voltadas ao acolhimento e humanização, através de oficinas realizadas de 2015 á 2017 em parceria com a Divisão de Educação Permanente em Saúde (DEPS), do estado de Santa Catarina. OBJETIVOS: Capacitar os profissionais de saúde sobre classificação de risco através da educação permanente em saúde. RELATO DE EXPERIÊNCIA: O município de Canoinhas possui uma população de 54.269 habitantes e faz parte da $25^{a}$ região de saúde do Planalto Norte, possuindo $48,85 \%$ de cobertura de atenção básica. Com seis estratégias de saúde da família distribuídas nos principais bairros da cidade, Campo da Água Verde, Alto das Palmeiras, Piedade, Cristo Rei e Cohab I. Na região interiorana, possui unidades básicas de saúde com equipe mínima para atender a população, além de uma unidade básica central a qual atende à demanda que não faz parte da área de abrangência das Estratégias de Saúde da Família.O agendamento para consultas médicas se dava da seguinte forma: agendamento prévio somente para idosos, os demais usuários eram agendados todos os dias através de fila no início do turno. Com o passar dos anos, as filas e demandas só foram aumentando, com isso os pacientes começaram a chegar cada vez mais cedo, tendo de enfrentar mudanças climáticas, número de

\footnotetext{
${ }^{1}$ Enfermeira no município de Canoinhas, pós-graduada em Gestão em saúde pública, pela UnC (Universidade do Contestado). Santa Catarina. Brasil. E-mail: grasycristina@hotmail.com

2 Enfermeira no município de Canoinhas, pós-graduada em Saúde Publica com área de concentração em Programa de Saúde da Família, pela UNC (Universidade do Contestado). Santa Catarina. Brasil. E-mail: rciupka@bol.com.br
} 
Agendamento com acolhimento e classificação de risco nas Unidades de Estratégia de Saúde da Família no Munícipio de Canoinhas-SC

vaga limitado e muitas vezes quem realmente necessitava de consulta não conseguia para aquele dia. Isso foi observado pelas equipes inúmeras vezes, gerando desconforto e angústia. Diante destas demandas as equipes de saúde observaram a necessidade de uma escuta qualificada e uma triagem classificando riscos. Verificaram ainda a necessidade de agendamento prévio de consultas e atendimento a demanda livre que acabava ficando reprimida e eram sempre encaminhadas ao Pronto Atendimento do município. Buscando através da educação permanente capacitações sobre acolhimento e humanização no atendimento. As capacitações foram realizadas para os profissionais dos treze municípios do Planalto norte Catarinense nos anos de 2015 e 2016. Em 2017 foi realizado para os profissionais da saúde do município de Canoinhas uma oficina sobre acolhimento, classificação de risco e humanização, a qual sensibilizou os profissionais das Estratégias de Saúde da Família da importância do acolhimento nas unidades. Estas capacitações foram realizadas pelos representantes da DEPS do estado de Santa Catarina, Sra. Maria de Fátima de Souza Rovaris e Sr. Fernando de Toledo Barros Wendhausen. O agendamento com classificação de risco foi implantado nas Estratégias de Saúde da Família, após as oficinas de capacitação aos profissionais dos ESF.Foram realizadas adaptações na classificação de risco condizendo com à realidade dos ESF. Pois o atendimento nas unidades é de promoção da saúde e prevenção à doença, salvo as exceções de atendimento curativo. A classificação vermelha que são os chamados encaixes, ou seja, consulta no dia é realizada pela equipe de enfermagem: enfermeiro e/ou técnico de enfermagem, os quais são capacitados para tal avaliação. As outras classificações: amarela, verde e azul, podem ser realizadas pela recepção ou agentes comunitários de saúde, os quais foram capacitados pela equipe de enfermagem para tais avaliações. Em Maio de 2017, foi instituído como projeto piloto na Estratégia de Saúde da Família Willy Radke (Alto das Palmeiras), a experiência com o agendamento por acolhimento com classificação de risco, buscando acabar com as filas para marcação de consulta médicas, promovendo a população um atendimento com escuta qualificada, priorizando queixas através de sinais e sintomas e colocando o indivíduo como responsável pela sua saúde. No mês de Junho/2017 na unidade Jair Côrte (Piedade) e em Julho/2017 na unidade do Campo da Água Verde, Cohab I e Unidade Central. Colocando a equipe a frente do trabalho, buscando desde a recepção até a equipe de enfermagem a avaliação e o acolhimento daqueles que buscam e utilizam o serviço de saúde. RESULTADOS: O projeto obteve êxito desde sua implantação e apresentou resultados positivos perante a opinião da população e da equipe de trabalho, a qual consegue organizar e atender com qualidade o indivíduo que procura o serviço de saúde; acabando com as filas para agendamento de consulta, diminuindo o tempo de espera do usuário, proporcionado escuta qualificada e avaliando sinais e sintomas. Comprovando ainda a efetividade da Educação Permanente em Saúde para os profissionais dessa área. CONCLUSÕES: Pode-se afirmar que após a implantação do acolhimento com classificação de risco houve o empoderamento da equipe, o qual tornou o clima de trabalho mais agradável, otimizou o tempo e proporcionou a equipe reuniões e espaços de discussões dos pontos que podem ser melhorados. Obtendo resolutividade dos serviços aos que utilizam as unidades de saúde. Vale ressaltar que a demanda da Unidade de Pronto Atendimento - UPA também teve queda significativa de procura por consultas rotineiras. Trabalhar com o tema classificação de risco no acolhimento na atenção primária por meio de oficinas educativas favoreceu a troca de conhecimentos entre os profissionais de enfermagem e demais trabalhadores da unidade, além de contribuir para atualização, conscientização e

Saúde Meio Ambient. v. 6, n. esp. (Anais Workshop), p. 27-29, dez. 2017 
motivação dos profissionais para o atendimento, demonstrando assim a importância da educação permanente nos serviços de saúde e a discussão sobre a necessidade de capacitação dos profissionais visando à qualificação do cuidado, a melhoria das condições de trabalho e proporcionando à população atendimento humanizado.

Palavras-Chave: Acolhimento. Escuta qualificada. Educação permanente. Classificação de risco.

Resumo recebido em: 08/12/2017

Resumo aprovado em: 17/12/2017

Resumo publicado em: 20/12/2017 